\title{
Chondrolaryngoplasty in transgender women: Prospective analysis of voice and aesthetic satisfaction of 15 patients
}

\author{
Mateus Aires ${ }^{1}$, Bruno Moraes $^{1}$, and Daniela Vasconcelos ${ }^{1}$ \\ ${ }^{1}$ Hospital das Clinicas
}

June 12,2020

\begin{abstract}
Key points: Chondrolaryngoplasty or "tracheal shaving" is cosmetic surgery to reduce the laryngeal prominence in transgender women. Chondrolaryngoplasty represents a challenge in seeking a balance between aesthetics and function: a very conservative resection of the thyroid cartilage may lead to aesthetic dissatisfaction, while excessive resection may destabilize the anterior commissure tendon, causing permanent vocal damage. This was the first study to assess fundamental frequency and GRBAS scale before and after the surgery and there was no permanent vocal change in any of the patients. The midpoint of the height of the thyroid cartilage was a simple, easy to perform and safe parameter to locate and preserve the anterior commissure. Smoothing the edges and flattening the residual laryngeal prominence with a $4 \mathrm{~mm}$ diamond burr enabled major remodeling without a temerarious resection. All 15 patients presented a positive variation in the visual analogue score for aesthetic satisfaction, with a mean improvement of $8.6 \pm 1.9$ out of 10 . Chondrolaryngoplasty led to significant aesthetic satisfaction in transgender women. The surgery caused no vocal change.
\end{abstract}

Title: Chondrolaryngoplasty in transgender women: Prospective analysis of voice and aestheticsatisfactionof 15 patients

\section{KEYPOINTS}

- Chondrolaryngoplasty or "tracheal shaving" is cosmetic surgery to reduce the laryngeal prominence in transgender women.

- Chondrolaryngoplasty represents a challenge in seeking a balance between aesthetics and function: a very conservative resection of the thyroid cartilage may lead to aesthetic dissatisfaction, while excessive resection may destabilize the anterior commissure tendon, causing permanent vocal damage.

- This was the first study to assess fundamental frequency and GRBAS scale before and after the surgery andthere was no permanent vocal changein any of the patients. The midpoint of the height of the thyroid cartilage was a simple, easy to perform and safe parameter to locate and preserve the anterior commissure.

- Smoothing the edges and flattening the residual laryngeal prominence with a $4 \mathrm{~mm}$ diamond burr enabled major remodeling without a temerarious resection.All 15 patients presented a positive variation in the visual analogue score for aesthetic satisfaction,with a mean improvement of $8.6 \pm 1.9$ out of 10 .

- Chondrolaryngoplasty led to significant aesthetic satisfactionin transgender women. The surgery caused no vocal change.

Keywords: Transgender Persons.Sex Reassignment Procedures. Plastic Surgery. Thyroid Cartilage. Voice.

\section{MAIN BODY}

\section{Introduction}


Gender dysphoria is estimated to occur in over 1 millionpeople in the United States. ${ }^{1}$ The laryngeal prominence demarcated in the cervical region, commonly known as the "Adam's apple", is one of the stigmatizing secondary sexual characteristics of men and it is a notable obstacle to the full exercise of transgender women's social and professional role. ${ }^{2}$

Chondrolaryngoplasty or "tracheal shaving" is cosmetic surgery to reduce the cervical projection of the laryngeal prominence, initially described by Wolfort and Parry ${ }^{2}$ in 1975.In retrospective studies, around $85 \%$ of patients submitted to chondrolaryngoplasty report improvements in the appearance of the laryngeal prominence and satisfaction with the scar. ${ }^{3}$ Complications, although rare, may include damage to the vocal folds and epiglottic destabilization. ${ }^{4}$

To the best of our knowledge, to date, there has been no prospective study in the literature that analyzes the aesthetic and functional results of chondrolaryngoplasty. Thus, the objectives of this research were to assess safety, consequence on voice quality, and effectiveness (i.e., subjective aesthetic satisfaction) of chondrolaryngoplasty in transgender women.

\section{Materials and methods}

Ethical considerations

This study was conducted in accordance with the Helsinki Declaration and was approvedby theethics committee of [Removed for blind review]. Informed consent was obtained from each patient.

Study design and patients

This was a prospective interventional cohort, conducted at the Hospital das Clínicas da UFPE, Recife, Brazil. The recruitment period was from March 2018 to October 2019. The population consisted of consecutive transgender women diagnosed with gender identity disorder, according to the criteria of the World Professional Association for Transgender Health Inc. ${ }^{5}$ monitored for at least 2 years in the hospital, with aesthetic dissatisfaction regarding the laryngeal prominence. The exclusion criteria establishedwere: presenting with clinical or psychiatric comorbidity prohibiting surgical treatmentor inappropriate physical characteristics for the procedure.

Pre- and Postoperative Assessment

Eligible patients were assessed by photographic records of the laryngeal prominence and laryngostroboscopyby a senior laryngologist (B.T.M). For subjective analysis of the laryngeal prominence, we useda visual analogue scale (VAS) for aesthetic satisfaction, graded from 0 (very ugly) to 10 (very beautiful), applied at the preoperative consultation and in the sixth postoperative month, based on the Utrecht questionnaire validated for aesthetic rhinoplasty. ${ }^{6}$

To assess the effects of the surgical procedure on vocal quality, voice recordings were made in the immediate preoperative period and on the thirtieth postoperative day,using Voxmetria ${ }^{\circledR}$ (CTS Play). The voice of each patient was recordedin an individual sound file and anonymously labeled. These samples were randomized, and voice assessment was performed blindly by one experienced listener, who did not participate in the research. We analyzed the fundamental frequency (F0) and the auditory-perceptual voice assessment with the Hirano GRBAS scale.

Technique

All patients were submitted to chondrolaryngoplasty under general anesthesia and orotracheal intubation, by the same team of otolaryngologists (B.T.M., M.M.A.C.), using the same surgical technique. A median transverse anterior cervical incision of $3 \mathrm{~cm}$ was made in a previous cervical cutaneous fold over the larynx and an upper and lower subplatysmal flap was created. After dieresis of the muscle planes, the thyroid cartilage was exposed. The external and internal perichondrium from the region of the laryngeal prominence to be resectioned were detached. The height of the thyroid cartilage was then measured and the midpoint of the distance between the thyroid notch and the lower margin of the thyroid cartilage (projection of the anterior 
commissure of the vocal folds) was identified, an area that must be preserved to avoid disinsertion of the vocal folds. After delimiting a safe margin of $3 \mathrm{~mm}$ above the midpoint of the height of the thyroid cartilage, the laryngeal prominence and the upper portion of the cartilage were resectioned in a "V" shape, also including the upper border along the thyroid notch. For this resection, a scalpel blade number 15 and/or a $2 \mathrm{~mm}$ surgical cutting burrwas used (if calcified cartilage, especially in patients aged over 40). After resection, a crucial step in this procedure was to smooth the edges and flatten the residual laryngeal prominence with a $4 \mathrm{~mm}$ diamond burr. Finally, the planes were then closed,followed by intradermal suture, without placing a drain (Figure 1).

Statistical Analysis

Statistical analysis was performed using SPSS ${ }^{\circledR} 23.0$ (IBM, Armonk, NY). Statistical significance was compared using a Wilcoxon signed rank test. Statistical significance was fixed at $\alpha=0.05$.

\section{Results}

A total of 15 patients were included. The mean age was $31.7 \pm 8.3$ years (range 22 to 51 years). The mean time of multidisciplinary monitoring at the service before undergoing chondrolaryngoplasty was 3.6 years (range 2 to 9 years). The mean number of surgeries prior to chondrolaryngoplasty was 1.2.

Laryngostroboscopy examinations were normal in all patients.

The average postoperative follow-up time was $15.3 \pm 6.1$ months (range 6 to 25 months).

Aesthetic Satisfaction

Fifteen (100\%) patients presented a positive variation in the VAS score when comparing the pre- and postoperative appearance of laryngeal prominence. Before surgery, 8 (53\%) patients had graded the appearance of the laryngeal prominence as 0 , while in the postoperative period, $10(67 \%)$ patients graded it as 10 (Figure 2). The mean value of the preoperative VAS was $0.7 \pm 1.0$ and postoperative, $9.3 \pm 1.1$, with a mean improvement of $8.6 \pm 1.9$, with statistical significance $(\mathrm{P}<0.001 ; 95 \%$ CI $7.3-9.6)$.

Voice Analysis

Voice analysis was performed with 11 patients, since 4 patients were excluded due to additional concurrent pitch-raising vocal surgery. In the assessed patients, the mean pre-operative fundamental frequency was 171.3 $\pm 41.2 \mathrm{~Hz}$ and in the post-operative, $177.1 \pm 39.5 \mathrm{~Hz}$, with a mean difference of $5.8 \pm 10.5 \mathrm{~Hz}$, with no statistical significance ( $\mathrm{P}=0.74 ; 95 \% \mathrm{CI}=-30.1$ to 41.7 ; Figure 3 ). There was no statistically significant difference in the GRBAS scale of the mean value of each of the five categories before and after surgery (Table $1)$.

Amongst the complications, one patient (7\%) presented with a hyperpigmented scar and two (13\%) reported hoarseness during the first postoperative week, which was overcome without the need for specific treatment. There were no major complications such as disinsertion of the epiglottis or vocal folds.

\section{Discussion}

Spiegel $^{7}$, in a retrospective study, indicated that $60 \%$ of the 31 patients who underwent chondrolaryngoplasty were "very" or "completely" satisfied. In our sample, all patients demonstrated aesthetic satisfaction after surgery, whereby $80 \%$ of the VAS scores were between 9 and 10 . We introduced the use of the diamond burrto flatten the remaining thyroid cartilage, thereby enabling major remodeling without a temerarious resection,perhaps one of the key points for surgical success.

It was demonstrated, prospectively and objectively, that there was no permanent vocal change in any of the patientsduring the postoperative period. Two patients reported hoarseness in the first week, possibly due to transient laryngeal edema from surgical manipulation or even by orotracheal intubation, which was resolved itself without the need for any specific treatment. The variation observed in the F0 and in the GRBAS had no statisticalsignificance and is probably part of the daily changes within the normal range of each individual. ${ }^{8}$ 
Chondrolaryngoplasty represents a challenge for the surgeon in seeking a balance between aesthetics and function: a very conservative resection of the thyroid cartilage may lead to aesthetic dissatisfaction, while excessive resection may destabilize the anterior commissure tendon, thereby signifying permanent vocal damage, with hoarseness and decrease in vocal pitch, which would be tragic for a transgender woman.

Spiegel ${ }^{5}$, in 2008, described a surgical approach using a laryngeal mask airway combined with intra-operative fiberoptic laryngoscopy examination to mark the implantation height of the anterior commissure in the thyroid cartilage with a 22-gauge needle, and consequently at the safe limit of the resection of the thyroid cartilage.In our study, the midpoint of the height of the thyroid cartilage was used as a parameter for insertionof the anterior commissure, with an additional safety margin of $3 \mathrm{~mm}$. This parameter had already been employed since Isshiki type I thyroplasty and was objectively measured by Sagiv ${ }^{9}$ in 2016 . It proved to be simple, easy to perform and safe. Furthermore, unlike Spiegel's technique, it can be executed under general anesthesia with endotracheal tube, especially when performing another sex reassignment proceduresimultaneously.

This study has several limitations. Initially, the number of participants was small, and might not have reliably represented the population. Secondly, due to the study design and ethical aspects, it was not possible to establish a control group to eliminate the influence of the placebo effect. Moreover, there was no objective measurement of the laryngeal prominence before and after surgery, demonstrating in fact that there was a significant reduction.

\section{Conclusion}

Chondrolaryngoplasty with resection of the laryngeal prominence was a safe and effective procedure for the aesthetic adequacy of transgender women, with significant patient satisfaction regarding the postoperative cervical appearance. The surgery caused no vocal change. There was no major complication of chondrolaryngoplasty in this study.

\section{REFERENCES}

1. Massenburg BB, Morrison SD, Rashidi V et al. Educational Exposure to Transgender Patient Care inOtolaryngology Training. J Craniofac Surg. 2018;29(5):1252-1257.

2. Wolfort FG, Parry RG. Laryngeal chondroplasty for appearance. PlastReconstr Surg. 1975;56:371-374.

3. Matai IV, CheesmanAD, Clarke PM. Cricothyroid Approximation and Thyroid Chondroplasty: A Patient Survey. Otolaryngology-Head and Neck Surgery, 2003;128(6): 841-847.

4. Spiegel JH, Rodriguez G. Chondrolaryngoplasty under general anesthesia using a flexible fiberoptic laryngoscope and laryngeal mask airway. Arch Otolaryngol Head Neck Surg. 2008;134(7):704-708.

5. World Professional Association for Transgender Health. Standards of Care for the Health of Transsexual, Transgender, and Gender Nonconforming People.7th ed. Minneapolis, MN: World Professional Association for Transgender Health, 2011. [accessedin 19 July 2019] Available at:http://www.wpath.org/documents/SOC\%20V7\%2003-17-12.pdf.

6. Francisco R, Lohuis JFM, Almeida J et al. Versão em português do "The Utrecht questionnaire for outcomeassessment in aestheticrhinoplasty": validação e aplicação clínica. Braz. J. Otorhinolaryngol. 2019;85(2):170-175.

7. Spiegel JH, Cohen MB, Insalaco LF, Tonn CR.Patient Satisfaction after Aesthetic Chondrolaryngoplasty.PlastReconstr Surg Glob Open. 2018;c6(10):e1877.

8. McGlinchey EL, Talbot LS, Chang K et al. The effect of sleep deprivation on vocal expression of emotion in adolescents and adults. Sleep. 2011;34(9):1233-41.

9. Sagiv D, Eyal A, Mansour J, Nakache G, Wolf M, Primov-Fever A. Novel anatomic characteristics of thelaryngeal framework: a computed tomography evaluation. Otolaryngology-Head and Neck Surgery, 2016 ; 154(4); 674-678.

Data Availability StatementThe data that support the findings of this study are available on request from the corresponding author. The data are not publicly available due to privacy or ethical restrictions. 
TABLES

\begin{tabular}{|c|c|c|c|c|}
\hline & $\begin{array}{l}\text { TABLE I } \\
\text { Overall Pre- } \\
\text { and } \\
\text { Postoperative } \\
\text { Voice } \\
\text { Assessments }\end{array}$ & $\begin{array}{l}\text { TABLE I } \\
\text { Overall Pre- } \\
\text { and } \\
\text { Postoperative } \\
\text { Voice } \\
\text { Assessments }\end{array}$ & $\begin{array}{l}\text { TABLE I } \\
\text { Overall Pre- } \\
\text { and } \\
\text { Postoperative } \\
\text { Voice } \\
\text { Assessments }\end{array}$ & \\
\hline & $\begin{array}{l}\text { Preoperative } \\
\text { Mean (SD) }\end{array}$ & $\begin{array}{l}\text { Postoperative } \\
\text { Mean (SD) }\end{array}$ & $\begin{array}{l}\text { Difference (CI } \\
95 \%)\end{array}$ & $\mathbf{P}$ \\
\hline Grade & $0.91(0.31)$ & $0.72(0.25)$ & $\begin{array}{l}-0.19(-0.07 \text { to } \\
0.43)\end{array}$ & .50 \\
\hline Roughness & $0.63(0.21)$ & $0.45(0.15)$ & $\begin{array}{l}-0.18(-0.01 \text { to } \\
-0.34)\end{array}$ & .30 \\
\hline Breathiness & $0.45(0.15)$ & $0.45(0.15)$ & 0 (-0.13 to 0.13$)$ & .97 \\
\hline
\end{tabular}

$\mathrm{SD}=$ Standard Deviation. $\mathrm{CI}=$ Confidence Interval.

\section{FIGURE LEGENDS}

Fig. 1: Surgical steps. A: surgical positioning with a cushion under the shoulders and a head ring to support the head. B: marking the area of the thyroid cartilage to be resectioned, $3 \mathrm{~mm}$ away from the midpoint of the cartilage height. C: cartilage appearance after resectioning the prominence. D: smoothing and flattening of the edges of the remaining thyroid cartilage. E: resected portion of the thyroid cartilage, in a "V" shape. F: immediate postoperative aspect of the surgical wound, in profile.

Fig. 2: VAS $=$ Visual AnalogueScale. Distribution of VAS grades for aesthetic satisfaction, before $($ mean $=$ $0.7 \pm 1.0)$ and after surgery $($ mean $=9.3 \pm 1.1)$. Mean variation $=8.6 \pm 1.9(\mathrm{P}<0.001 ; \mathrm{CI} 95 \%$ 7.3-9.6)

Fig. 3: F0 = fundamental frequency. $\mathrm{Hz}=$ Hertz. Mean $\mathrm{F} 0(\mathrm{~Hz})-$ Preoperative $=171.3 \pm 41.2 \mathrm{~Hz}$, and Postoperative $=177.1 \pm 39.5 \mathrm{~Hz}$. Each line represents 1 patient. Mean variation $=5.8 \mathrm{~Hz} \pm 10.5 \mathrm{~Hz}(\mathrm{P}=$ 0.74 ; CI $95 \%=-30.1$ to 41.7$)$. 


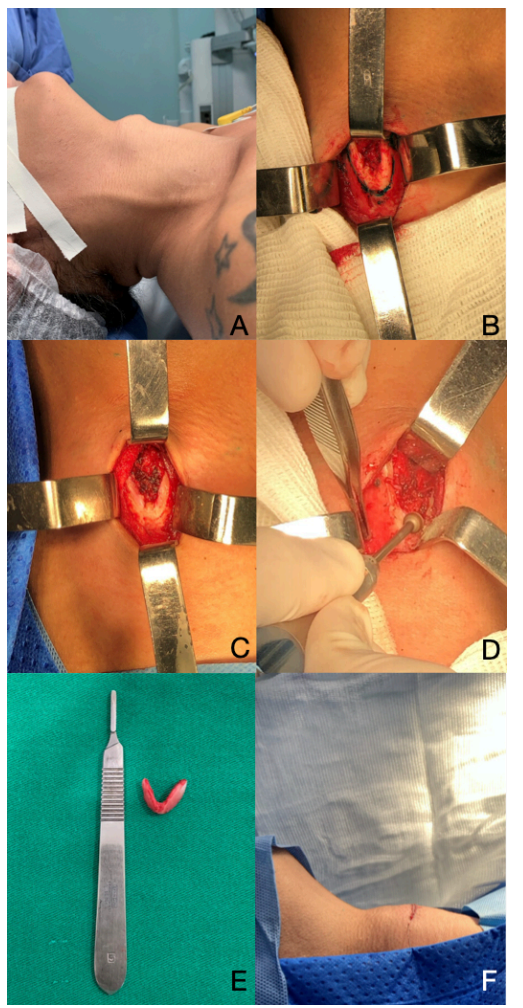

Fig. 1: Surgical steps. A: surgical positioning with a cushion under the shoulders and a head ring to support the head. B: marking the area of the thyroid cartilage to be resectioned, $3 \mathrm{~mm}$ away from the midpoint of the cartilage height. C: cartilage appearance after resectioning the prominence. D: smoothing and flattening of the edges of the remaining thyroid cartilage. E: resected portion of the thyroid cartilage, in a "V" shape. F: immediate postoperative aspect of the surgical wound, in profile. 


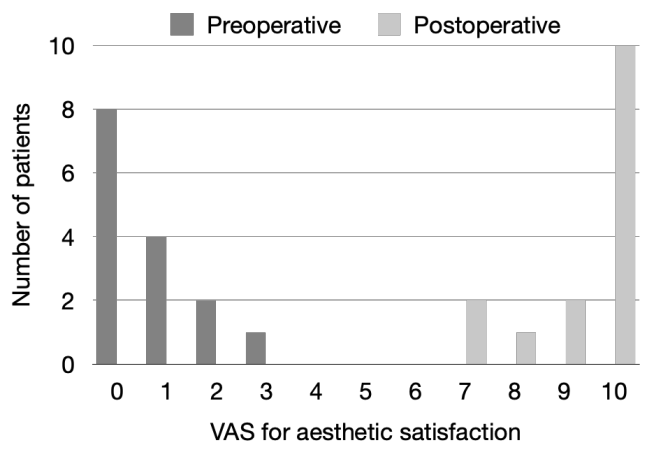

Fig. 2: VAS = Visual Analogue Scale. Distribution of VAS grades for aesthetic satisfaction, before $($ mean $=0.7 \pm 1.0)$ and after surgery $($ mean $=9.3 \pm 1.1)$. Mean variation $=8.6 \pm 1.9(\mathrm{P}<0.001 ; \mathrm{CI} 95 \% 7.3-9.6)$. 


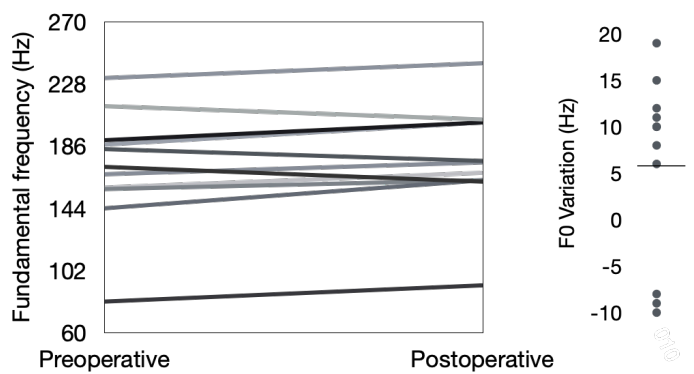

Fig. 3: $\mathrm{F} 0=$ fundamental frequency. $\mathrm{Hz}=\operatorname{Hertz}$. Mean $\mathrm{F} 0(\mathrm{~Hz})-$ Preoperative $=171.3 \pm$ 41.2 Hz, and Postoperative $=177.1 \pm 39.5 \mathrm{~Hz}$. Each line represents 1 patient. Mean variation $=5.8 \mathrm{~Hz} \pm 10.5 \mathrm{~Hz}(\mathrm{P}=0.74 ; \mathrm{CI} 95 \%=-30.1$ to 41.7$)$. 